\title{
Factors associated with the use of herbal medicines for oral problems by patients attending the clinics of the School of Dentistry, Federal University of Juiz de Fora, Brazil
}

\author{
Janice Simpson de Paula', Alexandre Marques de Resende², Fábio Luiz Mialhe ${ }^{3}$
}

${ }^{1} \mathrm{DDS}, \mathrm{MS}, \mathrm{PhD}$ student of Dentistry, Department of Community Dentistry, Piracicaba Dental School, University of Campinas (UNICAMP) Piracicaba, SP, Brazil

${ }^{2} \mathrm{PhD}$, Associate Professor, Dental School, Federal University of Juiz de Fora, Juiz de Fora, MG, Brazil

${ }^{3} \mathrm{PhD}$, Associate Professor, Department of Community Dentistry, Piracicaba Dental School, University of Campinas (UNICAMP), Piracicaba, SP, Brazil

\begin{abstract}
Aim: To evaluate differences in sociodemographic characteristics (gender, age, educational level and income) between users and nonusers of phytotherapy for dental purposes; the degree of population's knowledge of herbal medicines for dental needs; and whether patients inform the health professional about their use of phytotherapy. Methods: A questionnaire was applied to 100 patients in waiting rooms of the School of Dentistry of the Federal University of Juiz de Fora, in 2008, to inquire about sociodemographic variables and other factors associated with the use of phytotherapy. Statistical analyses were carried out using the chi square statistical test to calculate association between the variables, with 0.05 as level of significance. Results: It was observed that $64.8 \%$ of participants were women with a mean age of $43.9 \pm 15.1$ years. Phytotheraphy use for treatment of oral problems was reported by $37 \%$ of patients interviewed in this study. Significant differences were found between users and non-users of herbal medicines for oral problems, associated with the patient's age $(p<0.05)$ and previous experience with use of phytotherapy to treat general health problems $(p<0.001)$. Conclusions: The results emphasize the need for more scientific evidence of the efficacy of herbal medicinal products already incorporated in the popular knowledge to treat oral problems in order to make it an accessible and alternative method for prevention and therapy in dentistry.
\end{abstract}

Keywords: medicinal plants, dentistry, public health.

\section{Introduction}

Received for publication: July 16, 2012 Accepted: October 18, 2012

Correspondence to: Janice Simpson de Paula Departmento de Odontologia Social Faculdade de Odontologia de Piracicaba

Caixa Postal 52 - CEP: 13414-903

Piracicaba, SP,Brasil

E-mail: janicesimpsondp@yahoo.com.br
Herbal products have been used since antiquity by humans as a way to reach or recover health. Over the decades, many plants with biological and antimicrobial properties have been studied by pharmaceutical companies as sources for new phytotherapeutic agents ${ }^{1}$. Since the Declaration of the Alma-Ata in 1978, the World Health Organization (WHO) has expressed the need to appreciate the use of medicinal plants in public health systems, as some studies have indicated that almost $80 \%$ of world population uses these plants in primary care ${ }^{2-3}$.

In the first US national survey, Eisenberg, et al. ${ }^{4}$ reported an increase in the 
prevalence of the use of complementary and alternative medicine (CAM). In 1990, this prevalence in the American adult population was $33.8 \%$ and increased to $42.1 \%$ seven years later. As regards people using herbal therapies, the same author detected 10\% increase from 1990 to 1997. According to Druss, et al. ${ }^{5}$, the majority of people use CAM therapies in conjunction with the conventional medical treatment.

In Brazil, the population and municipal health systems have shown growing interest in the use of CAM since the 1980s. In 2006, the National Policy for Complementary and Integrative Practices within the Brazilian National Health System $^{6}$ was established. Among the practices, Traditional Chinese Medicine, Acupuncture, Homeopathy, Phytotherapy (herbal medicines), Anthroposophical Medicine and Thermalism-Crenotherapy have become prominent ${ }^{6}$.

The use of these practices has also been incorporated into Dentistry. Numerous studies have been conducted to evaluate vegetable species in Dentistry, natural agents that are economically feasible and provide effective alternatives for treating oral diseases ${ }^{1,7-8}$. Over the years, the Brazilian population has used different forms of plant extracts to treat diseases of the oral cavity ${ }^{9}$. Singh, et al. ${ }^{10}$ showed that the prevalence of oral diseases is high and medicinal plants are increasingly gaining attention because of their antimicrobial properties. Abdulwahab and Al-Kholani ${ }^{11}$ confirmed the increasing interest in natural products by presenting a study about a herbal dentifrice tested in a randomized trial, and demonstrating that there was no difference between using this dentifrice in comparison with the traditional one.

Although various studies have evaluated the reasons for and individual factors associated with the use of herbal remedies by primary care patients, the characteristics of the population that use herbal medicines for oral health problems are relatively unknown. However, by means of studies along these lines, health managers and researchers are able to find strategies for future studies on herbal medicines and health professional training. Thus, studies such as those of Tomazzoni et al. ${ }^{12}$ are encouraged in Dentistry because they support the inclusion of phytotherapies in the Brazilian public health care system.

The aims of this exploratory study were to evaluate: (1) differences in sociodemographic characteristics (gender, age, educational level and income) between users and nonusers of phytotherapy for dental purposes; (2) the degree of population's knowledge of herbal medicines for dental needs; and (3) whether patients inform the health professional about their use of phytotherapy.

\section{Material and methods}

The research project was submitted to and approved by the Research Ethics Committee (№ 336/2008) of the Federal University of Juiz de Fora, Brazil. The participants' consent was obtained for inclusion in the study.

The study had a cross-sectional research design and the sample was determined by convenience, selected from the patients present in the waiting room of all clinics of the
School of Dentistry, Federal University of Juiz de Fora, from August 2008 to November 2008. Juiz de Fora is one of the pioneering cities in the industrial state of Minas Gerais, Brazil, and its predominating economic sectors are industry and services. The city has about 570,000 inhabitants, spread over a wide range of socioeconomic backgrounds, of whom $98.91 \%$ have access to fluoridated water ${ }^{13}$.

A self-administered questionnaire was applied by a researcher before the scheduled visit. The survey instrument included questions about the patient's social and demographic characteristics, including age, sex, education, household income and use of phytotherapy for treatment oral and general health conditions (Figure 1).

For participation in the study, patients had to be at least 18 years of age and be under treatment at one of the dental school clinics. Patients who agreed to participate were given the survey questionnaire to complete on their own. The researcher was available onsite to answer any questions the patients had in order to help to improve their understanding of the questionnaire used in the survey.

Descriptive and statistical analyses were performed using SPSS statistical software version 17 (SPSS Inc., Chicago, IL, USA) for data analysis at a 0.05 level of significance. The chisquare test was used to test the association of phytotherapy use for oral health problems and the sociodemographic characteristics of the sample, such as gender, age and use of phytotherapy for other health problems.

1. Do you use phytotherapy for general health problems or treating oral problems?
2. Name of herbal medicine used for dental problems.
3. The main reason for using phytotherapy for oral health treatment.
4. Form of consumption of the plant: tea, mouthwash or tampons.
5. Duration of use
6. Satisfaction with this type of treatment
7. Adverse effects
8. Do you inform the health professional (physician or dentist) during the clinical
interview that you are using herbal medicines? If not, explain the reasons.
9. Do you desire to receive more information on the therapies with herbal

Fig. 1. Questions about use of herbal medicines for oral problems by patients present in the clinics of the School of Dentistry, Federal University of Juiz de Fora, Brazil.

\section{Results}

Of the 100 eligible study participants, $64.8 \%$ were women with a mean age of 43.9 years with standard deviation of \pm 15.1 years (age range: 18-78 years). The characteristics of the study sample, the use of phytotherapy for general health problems and its association with use of phytotherapy for oral health problems are summarized in Table 1.

Of all patients interviewed in this study, 71 affirmed that they used phytotherapy for general health problems and 37 were using some form of phytotherapy for treating oral problems.

In the association of phytotherapy with the sociodemographic characteristics of the sample, it was 
Table 1. Sociodemographic characteristics of the sample, use of phytotherapy for general health problems and its associations with the use of phytotherapy for oral health problems $(n=100)$

\begin{tabular}{|c|c|c|c|c|c|c|}
\hline & \multicolumn{6}{|c|}{ Use of phytotherapy for oral health problems } \\
\hline & \multirow[t]{2}{*}{$\mathrm{N}$} & \multicolumn{2}{|c|}{ No } & \multicolumn{2}{|c|}{ Yes } & \multirow[t]{2}{*}{$p$-value * } \\
\hline & & $\mathrm{N}$ & $\%$ & $\mathrm{~N}$ & $\%$ & \\
\hline \multicolumn{7}{|l|}{ Gender } \\
\hline Female & 75 & 45 & 71.4 & 30 & 81.1 & \multirow[t]{2}{*}{0.282} \\
\hline Male & 25 & 18 & 28.6 & 7 & 18.9 & \\
\hline \multicolumn{7}{|l|}{ Age groups } \\
\hline$\leq 30$ & 24 & 20 & 31.7 & 4 & 10.8 & \multirow[t]{3}{*}{0.007} \\
\hline 31 a 64 & 71 & 38 & 60.3 & 33 & 89.2 & \\
\hline$\geq 65$ & 5 & 5 & 7.9 & 0 & 0 & \\
\hline \multicolumn{7}{|l|}{ Educational Level } \\
\hline$\leq 8$ years & 52 & 29 & 46.0 & 23 & 62.2 & \multirow[t]{2}{*}{0.119} \\
\hline$>8$ years & 48 & 34 & 54.0 & 14 & 37.8 & \\
\hline \multicolumn{7}{|c|}{ Household Income per Month** } \\
\hline$\leq 2$ minimum wages & 60 & 35 & 55.6 & 25 & 67.6 & \multirow[t]{2}{*}{0.236} \\
\hline $\begin{array}{l}>2 \text { minimum wages } \\
\text { Use of phytotherapy for } \\
\text { general health problems }\end{array}$ & 40 & 28 & 44.4 & 12 & 32.4 & \\
\hline No & 29 & 28 & 44.4 & 1 & 2.7 & 0.000 \\
\hline Yes & 71 & 35 & 55.6 & 36 & 97.3 & \\
\hline
\end{tabular}

${ }^{*}$ Chi-square test

${ }^{* *}$ Brazilian minimum wage in effect at time of data collection $=$ US $\$ 290$

observed that the age group $(\mathrm{p}<0.05)$ and use of phytotherapy for general health problems $(p<0.001)$ were found to be significantly associated with use of phytotherapy for oral health problems.

The 37 patients using herbal medicines for dental problems mentioned 52 plants, listed in Table 2. The most common phytotherapy products reported as being used at present were Ipomoea batatas and Plantago lanceolata, for pain, inflammation, infection or swelling.

Table 3 presents the information about use the phytotherapy for oral health treatment. The main reason for using phytotherapy for oral health treatment was that it was recommended by family tradition $(78.4 \%)$, and in most cases the plants were obtained the plants were grown by the patients

Table 2. List of phytotherapy most commonly used in Dentistry by respondents of the study survey

\begin{tabular}{|c|c|c|c|}
\hline Popular name (in Portuguese) & Scientific Name & No. cited (\%) & Oral problem indications \\
\hline Folha de batata doce & Ipomoea batatas & $19(36.5 \%)$ & Pain, inflammation, infection and swelling \\
\hline Transagem & Plantago lanceolata & $10(19.2 \%)$ & pain, inflammation, swelling \\
\hline Terramicina vermelha & Alternanthera brasiliana & $2(3.8 \%)$ & Pain \\
\hline Arnica & Arnica montana & $2(3.8 \%)$ & Pain, infection \\
\hline Folha de algodão & Gossypium hirsutum L. & $2(3.8 \%)$ & pain, infection \\
\hline Hortelã & Mentha piperita L. & $2(3.8 \%)$ & pain \\
\hline Malva & Malva sylvestris & $2(3.8 \%)$ & inflammation \\
\hline Arruda & Ruta graveolens L. & $1(1.9 \%)$ & pain, infection \\
\hline Boldo & Peumus boldus & $1(1.9 \%)$ & infection \\
\hline Camomila & Chamomilla recutita & $1(1.9 \%)$ & Pain \\
\hline Cana de macaco & Dichorisandra thyrsiflora & $1(1.9 \%)$ & Pain \\
\hline Cinco folhas & Panax ginseng & $1(1.9 \%)$ & Pain \\
\hline Erva cidreira & Melissa officinalis & $1(1.9 \%)$ & Pain \\
\hline Folha de cana & Saccharum officinarum L. & $1(1.9 \%)$ & Pain \\
\hline Folha de tomate & Lycopersicum esculentum & $1(1.9 \%)$ & Pain \\
\hline Jaborandi & Pilocarpus jaborandi & $1(1.9 \%)$ & inflammation \\
\hline Maria-dormideira & Mimosa Pudica & $1(1.9 \%)$ & pain and inflammation \\
\hline Necroton & Allium cepa & $1(1.9 \%)$ & Pain \\
\hline Rebenta pedra & Phyllanthus niruri L. & $1(1.9 \%)$ & Pain \\
\hline Urucum & Bixa orellana & $1(1.9 \%)$ & inflammation \\
\hline TOTAL & & $52(100 \%)$ & \\
\hline
\end{tabular}


Table 3. Information about use the phytotherapy for oral health treatment.

\begin{tabular}{lcc}
\hline Question & Response & Frequency \\
$\begin{array}{l}\text { Main reason for using phytotherapy for oral } \\
\text { health treatment }\end{array}$ & Family tradition & $78.4 \%$ \\
& & \\
\hline Form of consumption of the plant & Indication from another person & $21.6 \%$ \\
\hline Duration of use & Mouthwash and tampons & $43.2 \%$ \\
& $<10$ days & $56.8 \%$ \\
\hline Satisfaction with this type of treatment & $>10$ days & $94.5 \%$ \\
& Yes & $5.4 \%$ \\
\hline Adverse effects & No & $100 \%$ \\
& Yes & $0 \%$ \\
\hline Informed the health professional (physician & No & $0 \%$ \\
or dentist) during clinical the interview of being & Yes & $100 \%$ \\
using herbal medicines & & $54.1 \%$ \\
& & \\
\hline
\end{tabular}

themselves $(56.8 \%)$. The users of phytotherapy for oral problems reported consumption of the plant in the form of tea (43.2\%), mouthwash and tampons (56.8\%). In almost all cases, the duration of use was up to 10 days. All patients who used medicinal plants for oral problems reported satisfaction with this type of treatment and absence of adverse effects. Among them, $54.1 \%$ affirmed that they generally informed the health professional (doctor or dentist) in the clinical interview that they were using herbal medicines.

The justifications for not reporting their use to the health professional were, in a descending order: the patient did not think it was important (6 participants); the professional did not ask (4 participants); the plant is not harmful to health (2 participants); tea is simple to take and it does not interfere with treatment (1 participant); some doctors do not like the patient to use medicinal plants (1 participant). Three participants did not justify the reason for not reporting the use of medicinal plants to health professionals.

Among all participants of the research, 94\% wanted more information on the therapies with herbal medicines for treating health problems.

\section{Discussion}

In the present study it was found that the majority of users of herbal medicines for oral problems were women between the ages of 31 and 64 years, with fewer than 8 years of schooling, and family income less of than two minimum wages. However, gender, educational level and household income were not signiûcantly associated with the use of medical plants for these problems.

This is similar to ûndings by Tam, et al. ${ }^{14}$ studying patients treated at dental clinics and dental practices in the U.K., and the study of Elder et al. ${ }^{15}$, which found no significant differences in the use of CAM therapies associated with the above-mentioned variables. On the other hand, Hasan, et al. ${ }^{16}$ found signiûcant associations between phytotherapy use for oral problems and age, educational level and income in a study on CAM users. In comparison with descriptive data in another Brazilian study, Santos et al. ${ }^{17}$, observed that the prevalence results were similar: most of the sample were women with family income of fewer than two minimum wages.

One of the most important findings of this study was the strong association $(\mathrm{p}<0.001)$ between use of herbal medicines for other general health problems and use for oral problems. As affirmed by Hasan, et al. ${ }^{16}$, the popularity of unconventional therapies indicated an increase in patients' preference for a holistic approach to health care. The research results showed that $71 \%$ of participants reported using herbal medicines for general health problems, proving the high popularity of this type of therapy.

This fact makes it important for health professionals to address the use of phytotherapy and unconventional therapies by their patients, by explaining the benefits and limitations of this type of treatment to them, and more importantly to establish whether there are any potential drug interactions or adverse drug reactions. Hasan el al. ${ }^{16}$ also proposed that conventional health practitioners should acquire and develop essential skills in the area of CAM practice and its education should be incorporated into the medical and health science curriculum.

The proportion of participants that related the use of phytotherapy for oral diseases was $37 \%$, but it was difficult to make a comparison with other results because there are few similar studies in the literature. In studies evaluating phytotherapy users, the authors found that $53 \%^{9}, 55 \%^{12}$, $26 \% 5,50 \%{ }^{10}$ of the studied samples used herbal medicines for general health problems. Only the study of Santos, et al. ${ }^{17}$ presents this data, stating that $80 \%$ of participants used herbs for dental problems.

A significant number of patients who reported using herbal medicines for oral health problems omitted this information from their physicians, pharmacists or dentists $(45.9 \%)$. Similar to the data found by Hasan, et al. ${ }^{16}$, Clay, et al. ${ }^{18}$ and Santos, et al. ${ }^{17}$, as these authors verified that $54.6 \%$, $20.6 \%$ and $77,5 \%$, respectively, of the patients did not inform their health care professionals about CAM use. In the study 
of Druss, et al. ${ }^{5}$ with patients who used CAM, $91.2 \%$ of patients reported that they did not inform the physician of their use of unconventional therapies. When relating these findings to those of the study of Viegas $\mathrm{Jr}^{19}{ }^{19}$, one can assume that the reason why many patients do not report the use of herbal health professionals may be due to the culture of selfmedication, very common among Brazilians.

The relevant number of patients who affirmed that they did not inform health professionals of their use of medicinal plants demonstrates their insecurity in discussing their other options of health care treatments in addition to those of traditional medicine. This information confirms the professionals' need to be aware of the profile of the population served and to include questions related to this topic in the patient's medical history in order to attribute the appropriate value to and popularity of the use of herbal medications.

According to the literature, Elder et al. ${ }^{15}$ confirmed that it is important for physicians to know about their patients' use of alternative medicine. Eisenberg et al. ${ }^{4}$, affirmed that it is a very common belief worldwide that 'herbal products' are safe. Spector et al..$^{20}$, Little ${ }^{21}$, Clay et al. ${ }^{18}$, Tam et al. ${ }^{14}$ and Santos et al. ${ }^{17}$ warned that dentists must be better informed of the adverse effects and contraindications of CAM, based on scientific evidences. In a study conducted in a health center, Genovés et al. ${ }^{22}$ found that one in every five patients being treated with medicines was also taking herbal medicines by self-medication, confirming that the health authorities and physicians should know and advise the population about the possible risks to health and the contraindications of these products.

Among all participants, 94\% wanted to be better informed about these therapies with herbal medicines for health problems, suggesting the need for more scientific evidence to be developed and transmitted to the population about the use of CAM. Little ${ }^{21}$ affirmed that clinical trials demonstrated that certain CAM treatments are effective and safe and they can be incorporated into conventional Medicine and Dentistry. Based on their use and popular knowledge, the important growth of phytotherapy within preventive and curative programs has stimulated the evaluation of the action of different plant extracts ${ }^{23}$.

Studies should be conducted and information disseminated to the population. In the present study, $79 \%$ of participants used medicinal herbs by family tradition, ignoring scientific data confirming their safety. Begnami and Mialhe $^{24}$ found that even with the advancement of pharmaceutical discoveries, the tradition of using medicinal plants was not abandoned. Therefore, this research presents the people's interest in this type of therapy and public health policies, such as the Policy for Complementary and Integrative Practices within the Ministry of Health in Brazil ${ }^{6}$, are valid as regards encouraging the use of herbal medicines.

For Palombo ${ }^{25}$, given the incidence of oral disease, increased resistance of bacteria to antibiotics, adverse affects of some antibacterial agents at present used in dentistry and financial considerations in developing countries, there is a need for alternative prevention and treatment options that are safe, effective and economical. The search for alternative products continues and natural phytochemicals isolated from plants used as traditional medicines are considered good alternatives $^{1,25}$.

However, the data of this research should be interpreted within the context of some limitations. The study was exploratory; the sample does not represent the entire population, since a convenience sample was used instead of identifying patients by a randomized sampling. This study did not include measures of quality of life or questions about patient satisfaction with the use of herbal medication exclusively in order to determine how the treatment with Phytotherapy interfered with patients' quality of life.

From the results of this investigation, it would appear that phytotherapy is a matter of great importance to the population, and is of interest to the different areas of health. Since the first step taken by the WHO in 1978, there have been a growing number of studies on medicinal plants throughout the world. The present study characterized the profile of the patients in the sample using and enjoying herbal remedies for oral problems, allowing new questions to be raised for other researches in this area, collaborating with the planning of public health services in dentistry.

The present study verified that a large number of patients use phytotherapy for the treatment of general health problems, and among them, $37 \%$ use it for the treatment of oral health problems. Previous history of use for general problems and the patient's gender were variables associated with use of herbal medicines for oral problems. The development of further studies is necessary to promote scientific evidence of the efficacy and safety of products already enshrined in popular knowledge in order to enable them to become accessible alternatives in public health services for the prevention and treatment of oral health problems. However, dentists need to be aware of their patients' use of herbal remedies, know their potential risks, side effects and possible drug interactions, in order to provide the population with the best care.

\section{References}

1. Groppo FC, Bergamaschi CC, Kogo K, Franz-Montan M, Motta RHL, Andrade ED. Use of Phytotherapy in Dentistry. Phytother Res. 2008; 22: 993-8.

2. Rosa C, Câmara SG, Béria JU. Representations and use intention of phytotherapy in primary health care. Cienc Saude Col. 2011; 16: 311-8.

3. Ministry of Health (Brasil). Decreto n. .5 .813 , de 22 de junho de 2006. Aprova a Política Nacional de Plantas Medicinais e Fitoterápicos e dá outras providências. Diário Oficial da União, Brasília, jun. 2006 [in Portuguese].

4. Eisenberg DM, Davis RB, Ettner SL, Appel S, Wilkey S, Rompay MV. Trends in alternative medicine use in the United States, 1990-1997: results of a follow-up national survey. JAMA. 1998; 280:1569-75.

5. Druss BG, Rosenheck RA. Association between use of unconventional therapies and conventional medical services. JAMA. 1998; 282: 651-6.

6. Ministry of Health (Brasil). PNPIC: Política Nacional de Práticas Integrativas e Complementares no SUS-Atitude de Ampliação de Acesso. Ministério da Saúde. Brasil, 2006 [in Portuguese].

7. Ramakrishna Y, Goda H, Baliga MS, Munshi AK. Decreasing cariogenic bacteria with a natural, alternative prevention therapy utilizing phytochemistry (plant extracts). J Clin Pediatr Dent. 2011; 36: 55-63. 
8. Pieri FA, Mussi MCM, Fiorini JE, Moreira MAS, Schneedorf JM. Bacteriostatic effect of copaiba oil (Copaifera officinalis) against Streptococcus mutans. Braz. Dent. J. 2012; 23: 36-8.

9. Oliveira FQ, Gobira B, Guimarães C, Batista J, Barreto M, Souza M. Plant species indicated in odontology. Rev Bras Farmacogn. 2007; 17: 466-76.

10. Singh J, Kumar A, Budhiraja S, Hooda A. Ethnomedicine: use in dental caries. Braz J Oral Sci. 2007; 6: 1308-12.

11. Abdulwahab I. Al-Kholani. Comparison between the Efficacy of Herbal and Conventional Dentifrices on Established Gingivitis. Dent Res. 2011; 8: 57-63.

12. Tomazzoni MI, Negrelle RRB, Centa ML. Fitoterapia popular: a busca instrumental enquanto prática terapêuta. Texto Contexto Enferm. 2006; 15: 115-21.

13. Brazilian Institute of Geography and Statistics. Available from: http:www.ibge.gov.br.

14. Tam KK, Gadbury-Amyot CC, Cobb CM, Williams KB. Differences between herbal and nonherbal users in dental practice. J Dent Hyg. 2006; 80: 1-10.

15. Elder NC, Gillcrist A, Minz R. Use of alternative health care by family practice patients. Arch Fam Med. 1997; 6: 181-4.

16. Hasan SS, Ahmed SI, Bukhari NI, Loon WC. Use of complementary and alternative medicine among patients with chronic diseases at outpatient clinics. Complement Ther Clin Pract. 2009; 15: 152-7.

17. Santos EB, Dantas GS, Santos HB, Diniz MFFM, Sampaio FC. Ethnobotanical studies of medicinal plants for oral conditions in the municipality of João Pessoa, Brazil. Rev Bras Farmacogn. 2009; 19: 321-4.

18. Clay PG, Clauson KA, Glaros A. Complementary and Alternative Medicine use by patients visiting a free health clinic: a single-site, pilot study. Cur Ther Res. 2004; 65: 481-94.

19. Viegas Jr, VF. Study of the medicinal plants consumption in the MiddleNorth Region of the Rio de Janeiro State: acceptance by health professionals and mode of use by the population. Braz J Pharmacogn; 2008; 18: 308-13.

20. Spector ML, Fischer M, Dawson DV, Holmes DC, Kummet C, Nisly NL et al. Complementary and alternative medicine usage by patients of a dental school clinic. Spec Care Dentist. 2012; 32: 177-83.

21. Little JW. Complementary and alternative medicine: Impact on dentistry. Oral Surg Oral Med Oral Pathol Oral Radiol Endod. 2001; 98: 137-45.

22. Genovés JS. Larrea VP, Gomis ER, Martínez-Mir I. Consumo de hierbas medicinales y medicamentos. Atenc Prim. 2001; 28: 311-4.

23. Santos RL, Guimarães GP, Nobre MSC, Portela AS. Analysis about phytotherapy as an integrating practice in the Brazilian Unified Health System (UHS). Rev Bras Plantas Med. 2011; 13: 486-91.

24. Begnami AF, Mialhe FL. Survey of medicinal plants and their application in the municipal district of Piracicaba-SP. Rev Uning. 2008; 18: 49-62.

25. Palombo EA. Traditional medicinal plant extracts and natural products with activity against oral bacteria: potential application in the prevention and treatment of oral diseases. Evid Based Complement Alternat Med. 2009; 10: $1-15$ 